\title{
O ENIGMA DO ESPAÇO: UMA ENTREVISTA COM DAVID HARVEY
}

David Harvey está, sem sombra de dúvida, no rol dos intelectuais mais argutos e influentes dos dias atuais. Suas reflexões têm orientado os passos em várias áreas do conhecimento, penetrando tanto na vida acadêmica quanto no mundo social. Qualquer levantamento, ainda que preliminar, sobre sua trajetória indica uma farta produção bibliográfica - já traduzida em diversos idiomas -, bem como uma notável articulação com os movimentos sociais, o que deixa clara sua faceta de intelectual público.

Inglês, de Kent, fez toda a sua formação em Cambridge. Como ele próprio assume, um ponto de inflexão ocorreu em sua vida intelectual com a mudança para os Estados Unidos, em plena efervescência dos anos I960. Lá, foi fortemente impactado pelos movimentos por direitos civis eclodidos nas cidades americanas. Distinguished Professor da Universidade da Cidade de Nova York (CUNY), desde 200I, Harvey teve passagens anteriores por Universidades como Johns Hopkins e Oxford.

Desde cedo se interessou pelos estudos relacionados à problemática espacial, tornando-se geógrafo. Contudo, seus trabalhos têm se notabilizado para além dos círculos mais restritos da geografia, atingindo áreas contíguas de pesquisa, inovando a reflexão sobre o social. Ao conjugar às preocupações acerca do espaço elementos como a política, as relações internacionais, a economia e a filosofia, o autor foi capaz de aglutinar leitores e interessados das mais diversas áreas. 
Suas reflexões críticas auxiliam, em muito, o desvelamento de processos e relações, em seus contornos espaciais, trazidos pelas novas formas de acumulação capitalista. Com isso, Harvey é um dos responsáveis diretos pela oxigenação experimentada pelo pensamento marxista nas últimas três décadas. Cerrando fileiras com Fredric Jameson, Erik Ollin Wright, Michael Burawoy e Mike Davis, Harvey forma uma espécie de núcleo, heterogêneo, que recupera de maneira desafiadora e renovada a obra de Karl Marx e seu legado. Recentemente, ele tem se empenhado em popularizar, em alto nível, o pensamento de Marx através da publicização de seus cursos, extremamente disputados, sobre O capital. Na linha de retomada de temas clássicos, relevantes para a caracterização de nosso tempo, Harvey empenha-se também, com ênfase no âmbito internacional, em uma tentativa de reconstrução da teoria das crises do sistema capitalista e na análise do que conceitua como novo imperialismo.

Em 20I 2, no Brasil para o lançamento e divulgação de seu livro 0 enigma do capital, Harvey atraiu cerca de I.300 pessoas ao Instituto de Filosofia e Ciências Sociais da UFRJ e, já então, antecipava algumas das questões fulcrais presentes nos movimentos que insurgiriam o país nas manifestações de 2013. Na ocasião, o autor concordou prestimosamente em conceder esta entrevista, pouco antes de falar ao público carioca. Relato de vida, mas também monografia de um tempo - como talvez dissesse Antonio Gramsci -, que os leitores têm agora a oportunidade de conferir.

Marco Aurélio Santana \& Igor Peres. Embora o senhor seja um dos responsáveis pela difusão, em nível internacional, do pensamento de Karl Marx, seu contato com a obra do autor se deu tardiamente quando tinha 35 anos. Gostaríamos de saber, durante seus anos de formação em Cambridge, que tipo de literatura lhe foi mais influente.

David Harvey. De início, estive interessado em geografia histórica e, como um geógrafo histórico, eu lia intensamente acerca da história da Humanidade, mas com uma perspectiva arqueológica. Circulavam naquele tempo, e ainda circulam, livros de que me lembro agora e dos quais, talvez, sempre me lembrarei, como Man makes himself (1936), de Gordon Childe. A questão é que, desde os primeiros passos de minha formação, eu estava interessado na dinâmica evolucionária das sociedades, em como elas mudam. E, a partir daí, tinha um espectro amplo de leituras em história econômica, particularmente acerca do Mediterrâneo, mesmo antes do aparecimento do livro de Fernand Braudel. Mas, o Mediterrâneo era apenas uma arena na qual ocorria um conjunto de processos evolucionários. Eu me recordo de ler bastante também acerca das relações entre o desenvolvimento do comércio mundial e o da Inglaterra. Além disso, sobre o desenvolvimento de Flandres em relação ao desenvolvimento da Itália. Mesmo naquela época, isso não se tratava de um processo global, mas, de todo modo, se tratava de uma ampliação geográfica nesta direção. Eu acho 
que, a partir destas leituras, comecei a alinhar certas ideias sobre a natureza e a dinâmica cambiante de tempo e espaço. Há cerca de cinco anos, voltei-me para algumas daquelas coisas que eu guardava dos tempos de Cambridge, meus primeiros escritos, ainda para meu orientador, e percebi que já eram sobre a natureza da relação tempo e espaço, e pensei: "Deus do céu, desde os meus dezoito anos eu escrevo sobre tais questões. Que coisa!".

M.A.S. \& I.P. Por motivos evidentes, ligados à sua formação, sua reflexão sempre foi geograficamente informada. Mas, tentando pensar de uma forma mais abrangente, e para além dos campos de especialização, qual a importância heurística do espaço para a teoria social e por que é, em sua opinião, tão importante pensá-lo ou lidar teoricamente com ele?

D.H. Bem, primeiro eu diria que sempre achei complicado o fato de que muito da teoria social com a qual lidava apenas tratava o espaço como uma espécie de palco no qual as coisas evoluíam. Mas, me ficou claro, a partir de uma série de estudos por mim realizados que, na verdade, era o palco que se alterava, que estava sendo reconstituído e se transformava perpetuamente. Então, passei a refletir sobre a natureza cambiante das relações espaciais. Isso me pareceu uma maneira diferente de pensar as questões com as quais trabalhava. Pensá-las assim me pareceu melhor. Na teoria social convencional, por exemplo, em Max Weber ou Talcott Parsons, pode-se procurar em vão por qualquer tipo de relatividade e espaço, ou acerca do que ocorre com a dinâmica e a mudança nas relações espaciais ou, ainda, o que se passa quando olhamos a natureza da revolução nos transportes que não pode ser dissociada daquelas preocupações. Minha tese de doutorado, que foi sobre a agricultura no século XIX, mostrou que o desenvolvimento das ferrovias teve um papel significativo neste processo. Não apenas no transporte de commodities, mas também nos fluxos de informação. Como um doutorando, o que fiz foi ler os jornais locais de I8I5 até I874. Li cada edição do jornal semanal. O que surgiu dali foi uma clara percepção da transformação da natureza do jornal local. Ele se converte de uma espécie de reprodução do London Times, com uma série de anúncios sobre a venda de propriedades, em uma vibrante representação da opinião da sociedade sobre a agricultura local, lutas em torno de legislações sobre o milho, tarifas do açúcar, o papel do governo na agricultura, políticas de taxação etc. Obviamente, uma forte cultura regional local emergia. Contudo, com o advento das ferrovias, em I875, os tabloides ingleses tomaram conta do cenário. A comunicação não era mais uma coisa vibrante, restringindo-se, então, a coisas como casamentos locais e noticiário de crimes. Então, havia esta evolução, e o que os jornais estavam fazendo era representar as mudanças nas configurações de tempo, espaço, conhecimento e comunicação, em suas inter-relações. São coisas que sempre achei importantes e que, ao meu juízo, eram lacunares na teoria social. 
M.A.S. \& I.P. E no caso da tradição marxista podemos apontar esta mesma lacuna? Por quê?

D.H. Sim, eu acho. Em certo sentido porque O capital (I867) de Karl Marx, é constituído de uma crítica da economia política clássica; e, na exata medida em que esta não era uma questão levada tão a sério pela economia política clássica, isto foi herdado por Marx. "Capital" é uma abstração teórica, mas uma das coisas que Marx faz é dizer que o capital não tem pátria, que o capital se estabelece por todo o globo. Enfim, não é lá muita coisa. Friedrich Engels, por seu turno, no afamado A situação da classe trabalhadora na Inglaterra (I845), notadamente quando trata da questão da moradia, contribuiu indicando que a burguesia tinha só um jeito de solucionar este problema: movendo-o, mudando-o de lugar - aliás, foi de onde retirei algumas de minhas questões. De toda forma, eles fazem muito pouco no que se refere às relações espaciais. Eu avalio que a tradição marxista seguiu a mesma trilha até, claro, as formulações de Lênin acerca do imperialismo, quando se torna uma grande questão. A relação entre a formulação de Lênin de que uma parte do mundo estava explorando outra; e a de Marx, de que uma classe explorava outra classe, precisava ser enfrentada. Impressiona como ninguém na tradição marxista discutiu isso frontalmente. Então, nos anos I970, eu decidi enfrentar tal questão. Muitos marxistas, ainda hoje, não tratam de forma séria a diferenciação geográfica e nem mesmo outras questões com as quais venho trabalhando. Quando comecei a operar com o marxismo havia pouca preocupação acerca da urbanização e com as questões ambientais. Ambas cruciais para meus interesses. Então, de certa maneira, foi uma batalha fazer com que os marxistas assumissem seriamente o ângulo geográfico. De forma jocosa gosto de dizer que foi mais fácil trazer o marxismo para a geografia do que tem sido levar a geografia para o marxismo. Não era um ajuste fácil. Isso me levou a reformular e reconfigurar alguns dos argumentos básicos de Marx num modelo bem mais pé no chão, menos abstrato. Minha agenda foi me apropriar mais dele do que das grandes abstrações, fazendo-as trabalhar num mundo geograficamente diferenciado.

M.A.S. \& I.P. Buscando esclarecer os leitores sobre aproximações, distanciamentos, continuidades e rupturas acerca desta temática, como o senhor vê as suas reflexões sobre o espaço comparativamente às de Henry Lefebvre, que tratou de tais questões anteriormente?

D.H. Bem, como sabemos, muitas pessoas falavam sobre a produção do espaço nos anos I960. Se olharmos retroativamente para a literatura sobre planejamento, teremos autores, como John Friedmann, que tratavam do processo dinâmico de reprodução do espaço, com foco no desenvolvimento e nas relações entre espaço e integração. A teoria do desenvolvimento foi um aspecto muito significativo do planejamento regional. Era uma coisa que já estava lá. Hoje, a história intelectual diz que tudo começou com Lefebvre. Mas, se voltarmos 
para trás e falarmos disso de forma distinta, poderemos localizar outras pessoas e influências. Em meu Social justice and the city (1973) uso noções de Ernest Cassirer acerca de tempo e espaço, que são muito próximas das de Lefebvre. Eu sempre acho que Lefebvre retirou, sem dar créditos, algumas de suas ideias de Cassirer, porque, muitas vezes, os franceses fazem isso: retiram ideias de outros autores sem dar os devidos créditos. O que eu acho é que Lefebvre tentou integrar estas ideias com um conjunto já estabelecido de questões da tradição marxista, particularmente as contradições rural/urbano, as noções de vida camponesa, ou que estava ocorrendo com ela etc. Então, Lefebvre tentou também politizar a questão da reprodução do espaço. Já era óbvio na literatura sobre planejamento que quem produzia o espaço era o capitalista. Eles produzem um espaço que facilite seu propósito social, que pode ser desenvolvimento econômico, crescimento econômico, podendo ser também maior desigualdade social. O que Lefebvre fez muito bem foi criticar os planejadores do Estado que então produziam o espaço. Ele julgou necessário criticá-los, e acabou por influenciar grupos de geógrafos que estavam então começando a operar dentro de uma perspectiva crítica.

M.A.S. \& I.P. O debate sobre a assim chamada pós-modernidade varreu o cenário intelectual internacional entre os anos I980 e I990. Em seu bojo ele agregou destacados intelectuais, dentre os quais: Jürgen Habermas, Jean-François Lyotard, Anthony Giddens, Fredric Jameson e Perry Anderson. Em meio às polêmicas, o seu livro The condition of postmodernity (I989) foi considerado um divisor de águas. De seu ponto de vista, qual seria a sua contribuição particular a esta discussão?

D.H. Penso que minha contribuição particular foi exatamente me comportar como um marxista vulgar - condição em relação à qual, em verdade, quero me distanciar -, dizendo: se alguma coisa está mudando, quais são as condições econômicas desta mudança? Propunha exatamente uma investigação das origens da mudança cultural. Isso significava, portanto, olhar para a flexibilização do mercado de trabalho e para outras mudanças que estavam ocorrendo na economia naquele momento. Minha outra contribuição foi indicar em que grau a pós-modernidade estava descobrindo o espaço de forma particular, enfatizando demasiadamente diferenças e particularidades, bem como reforçando a impossibilidade de metateorias. Fiquei bastante contrariado com isso porque fui formado em um tipo de geografia que recusava integralmente qualquer metateoria. Aquilo era pura e simplesmente acerca da particularidade. Eu olhava para aquelas pessoas e pensava: "devem estar loucos se querem voltar para um mundo constituído intelectualmente pelo tipo de geografia em que eu fui educado". Então, busquei integrar as noções de espaço e tempo ao que seria o debate central. A estrutura do livro é simples: pós-modernidade, economia e o nexo espaço e tempo. Ele acabou sendo eficaz, tendo bastante impacto, surpreendentemente 
para mim. Achei sinceramente que ninguém fosse lê-lo. Finalmente, ele acabou sendo traduzido em várias línguas e eu fui enormemente citado.

M.A.S. \& I.P. Movendo-nos para outro campo de discussão, mas ainda posicionados no interior dos interesses da teoria social, desejamos saber, em sua opinião, qual o lugar e o papel de uma teoria crítica na sociedade contemporânea? D.H. Creio que esta é uma tradição que necessita desesperadamente ser reavaliada e revitalizada. Penso que uma questão a ser levada em conta seja a existência, hoje, de muitas teorias críticas. Todo acadêmico é, de certa forma, um teórico crítico, porque é geralmente crítico de seus colegas. Uma das coisas interessantes da Escola de Frankfurt era que tinha certa coesão com relação ao que estava tentando fazer. Desde então, a teoria crítica se fragmentou: estudos culturais, estudos raciais, estudos de gênero, estudos de orientação sexual. A teoria crítica misturou-se com política de identidade e, claro, muita coisa relevante e progressista surgiu a partir daí. Mas, o que ocorreu também foi que certa teoria crítica tornou-se antimarxista e antieconomia política. O resultado disso foi que muitos se afastaram da crítica da economia política, dirigindo-se a outros estudos críticos, o que nos deixou despreparados para entender, por exemplo, as crises recentes do capitalismo de 2007 e 2008 . Creio que a teoria crítica tem de começar a pensar como enfrentar conjuntamente a construção de um projeto coletivo. Eu gostaria de ver emergir um projeto político mais centrado em torno da teoria crítica, a partir da ideia geral do que significa ser anticapitalista, que não significa necessariamente ser marxista. Contudo, eu diria, dependendo das formas como se persiga este caminho, encontraremos considerável resistência.

M.A.S. \& I.P. O senhor tem mantido uma estreita relação com os movimentos sociais, se posicionando, de forma regular e incisiva, em debates públicos pelo mundo. Pensamos, por exemplo, em sua participação no Fórum Social Mundial, realizado no Rio de Janeiro, em 2009, e, mais recentemente, a partir de $20 \mathrm{II}$, em sua intervenção na discussão acerca dos rumos do movimento de contestação que ficou conhecido como Occupy. Neste sentido, como o senhor pensa a relação entre intelectuais e movimentos sociais?

D.H. Como acadêmico eu existo em um ponto determinado da produção, que é a produção e reprodução do conhecimento, bem como existem lutas que precisam ser travadas. Tenho tentado explicar às pessoas que a academia não é uma Torre de Marfim na qual nos sentamos. Nós estamos travando batalhas constantemente. Um dos projetos que tenho é manter um espaço aberto no interior da academia, no qual um pensamento crítico, como o de Marx, possa florescer. Isso não é fácil de fazer. É uma luta. Eu não espero que alguém que esteja envolvido na luta por habitação, ou quaisquer tipos de enfrentamento, deixe de fazê-lo, venha e se sente comigo em uma reunião da faculdade para 
discutir quem está certo sobre um determinado ponto. A questão que surge é como construir uma aliança entre o que nós estamos fazendo e o que eles estão fazendo, para estarmos juntos sem nunca tentar dizer a eles o que eles têm de fazer. Da mesma forma que não espero que eles me digam o que fazer. Mas, existem muitas possibilidades de aproximação e associação. Nós podemos manter uma relação forte com pessoas vinculadas ao trabalho, aos sem-teto etc. Neste sentido, existem muitas áreas de interseção e aliança, inclusive mobilizando certos recursos disponíveis aos que estão dentro da academia, como a capacidade para empregar certo tempo livre ou promover determinadas atividades. O que faço na City University of New York (CUNY) é dizer para os movimentos sociais: "se precisam de espaço para apresentar ideias, nós arranjaremos aqui". A administração atual não é tão amigável a este respeito, mas, por um período, eles nos deixaram fazer todo tipo de atividade. Assim, pessoas da comunidade podiam vir até a CUNY e travávamos proveitosos diálogos. Outra área que tem sido importante para mim é a orientação de trabalhos de pós -graduação. Temos alunos que atuam em movimentos sociais ao mesmo tempo em que desenvolvem suas teses. Eles acabam se envolvendo, eventualmente, nos mais variados conflitos, e nós os ajudamos de diversas maneiras. Eles me ensinam muito acerca do que se passa nos movimentos em que atuam. E não apenas os de pós-graduação, os de graduação, algumas vezes, nos colocam questões importantíssimas, as quais, uma hora ou outra, temos de enfrentar. Minha visão foi sempre a de que minha atividade primeira era, obviamente, no interior da universidade e por dentro do sistema acadêmico universitário. Mas sempre achei também que as melhores ideias surgiam da participação, do apoio e do envolvimento com os movimentos sociais. Eles sabem que colocam ótimas questões.

M.A.S. \& I.P. O seu livro Rebel cities (2012) tem estimulado debates, dentro e fora da academia, acerca da natureza, contornos e perspectivas dos espaços urbanos ao redor do globo. Nele se realça a importância da participação política para a construção do que seriam espaços públicos efetivos, ou seja, espaços comuns. Como o senhor vê o futuro das cidades e o papel dos movimentos sociais nele?

D.H. A cidade capitalista atingiu um ponto que é uma verdadeira abominação. Creio que alguma coisa realmente precisa mudar drasticamente no que respeita à urbanização, estratégias urbanas e mesmo do ponto de vista da dinâmica capitalista, a qual cria oportunidades para que forças de oposição apontem determinados caminhos, em vez de outros. Aqui no Rio de Janeiro, vocês passam por um conjunto de processos que parecem bastante problemáticos com relação às favelas, aos jogos Olímpicos e à Copa do Mundo. Estas intervenções sempre vêm acompanhadas pelas justificativas do Estado de que atua para o desenvolvimento. A questão não é só dizer que se tem direito à cidade. É preciso lutar 
por isso. De quem é o direito? Dito sem maiores qualificações, como um slogan vazio, parece que é só assumir tal direito. Mas sempre haverá conflito acerca deste direito. O fundamental é que os mais pobres possam influenciar os destinos da cidade tanto quando os mais ricos. Por isso, insisto que temos de olhar o urbano como um fenômeno de classe. O capital financeiro levantando condomínios, escritórios etc. está produzindo a cidade. Se quisermos resistir a esta maneira de produção, então temos de lutar contra este poder. Eu acho que se pode dizer, de certa perspectiva, que não há espaço público na cidade. Ele está inteiramente controlado pelo poder político. O espaço público nunca é não-regulado. Por isso, uma das grandes arenas de contestação é abrir este espaço público para o uso público de fato. É claro que a rua sempre foi um dos grandes espaços abertos para o ativismo político, o que vem sendo crescentemente diminuído. Uma das questões que envolvem os movimentos sociais não é deixar de defender os espaços públicos nas formas em que eles existem, mas, exatamente, criar novos, nos quais eventos públicos possam existir. As lutas sobre o conceito de espaço público e sobre a regulação do espaço público são arenas de conflito e disputa pela vida urbana. A essência da grande vida urbana e da vida cívica, para mim, é a livre articulação de pessoas, nas mais diversas formas, abrindo espaços para as possibilidades de variadas modalidades de encontros. Se isto não ocorre, é crítico para os movimentos liberar tais espaços comuns para a sua participação. Os movimentos podem fornecer uma abertura vital para uma ampla política por espaços comuns. São necessárias alianças, e quanto mais se torna aceitável a liberação dos espaços públicos para todos os propósitos públicos, mais abertas se tornam as possibilidades democráticas para os espaços da cidade, ou das regiões metropolitanas como um todo, no sentido de tornarem-se bens políticos comuns. Mas, existem obstáculos a tais processos que também precisam ser enfrentados, tais como os movimentos filofascistas europeus que ocupam o espaço em nome de uma política de exclusão espacial. $\mathrm{Na}$ cidade repousa nosso futuro político de esquerda. 
Marco Aurélio Santana é professor do Departamento de Sociologia e do Programa de Pós-Graduação em Sociologia e Antropologia do IFCS/UFRJ. Publicou, entre outros, Homens partidos: comunistas e sindicatos no Brasil (200I), Além da fábrica: trabalhadores, sindicatos e a nova questão social (co-organizado com José Ricardo Ramalho, 2003) e Bravos companheiros: comunistas e metalúrgicos no Rio de Janeiro (I945-I964) (2012).

Igor Peres é bacharel em Ciências Sociais pelo Instituto de Filosofia e Ciências Sociais da Universidade Federal do Rio de Janeiro (IFCS/UFRJ), licenciado pela mesma Universidade e mestre em Sociologia pelo Instituto de Estudos Sociais e Políticos (IESP/UERJ), com bolsa do CNPq. 


\section{O ENIGMA DO ESPAÇO: UMA ENTREVISTA COM DAVID HARVEY}

Resumo

A entrevista foca aspectos da vida intelectual de David Harvey. Reconstruindo seu percurso desde os primeiros anos na Universidade de Cambridge, onde se deu sua formação, passando por diálogos teóricos com nomes como Henry Lefebvre, destaca-se a centralidade do tema do espaço em seus trabalhos, sua proposta de reconstrução de conceitos provenientes do marxismo e o traço público de seu fazer intelectual.

THE ENIGMA OF SPACE: AN INTERVIEW WITH DAVID HARVEY

Abstract

The interview focuses on aspects of the intellectual life of David Harvey. Rebuilding his journey from the early years at Cambridge University, where he graduated, passing by theoretical dialogues with names like Henry Lefebvre, it highlights the centrality of the issue of space in his works, his proposal for reconstruction of concepts from Marxism and the public character of his intellectual practice.
Palavras-chave

David Harvey;

Capitalismo; Espaço;

Teoria social;

Movimentos sociais.
Keywords

David Harvey;

Capitalism; Space;

Social theory;

Social movements. 